\title{
Ply stacking sequence optimization of composite driveshaft using particle swarm optimization algorithm
}

\author{
K. Manjunath* and T. Rangaswamy \\ Department of Mechanical Engineering, Government Engineering College, Hassan 573201, India
}

Received 24 October 2011 / Accepted 13 November 2013 / Published online 26 February 2014

\begin{abstract}
In this paper an attempt has been made to optimize ply stacking sequence of single piece E-Glass/Epoxy, HM Carbon/Epoxy and Boron/Epoxy composite drive shafts using particle swarm optimization (PSOA). PSOA programme is developed using MATLAB V 7 to optimize the ply stacking sequence with an objective of weight minimization. The weight savings of the E-Glass/Epoxy, HM Carbon/Epoxy and Boron/Epoxy shaft are $51 \%, 87 \%$ and $85 \%$ of the steel shaft respectively. The optimum results of PSOA obtained are compared with results of genetic algorithm (GA) and found that PSOA yields better results than GA.
\end{abstract}

Key words: Composite driveshaft, PSOA, Ply stacking sequence, MATLAB, Optimization, GA.

\section{Introduction}

Now a days composite material are preferred in automotive applications because of their high strength to weight ratio, high stiffness to weight ratio and other designable properties compared with metals. Composite drive shaft applications have received new impetus during last decade. As composites are increasingly used, optimization technique becomes more and more important in the design of laminate because of the complexity and enormous design space.

In structural optimization, a number of efficient optimization algorithms like genetic algorithm, simulated biological growth, simulated annealing, ant colony, particle swarm algorithm, etc., mimicking natural phenomena and physical processes have been applied. Park et al. [1], Rajendran and Vijayarangan [2], Rangaswamy et al. [3, 4] have used genetic algorithm (GA) for ply stacking sequence optimization. It is a search technique used to find the solutions for optimization problems. It has excellent ability and better chances of finding optimum values, but it has complex operation procedure (inheritance, mutation, natural selection, and crossover) and low efficiency. GA has a tendency to converge towards local optima rather than the global optimum of the problem.

Recently particle swarm optimization has become a common heuristic technique in the optimization community, with many researchers exploring the concepts, issues, and applications of the algorithm. PSOA is an evolutionary computation technique developed by Kennedy and Eberhart [5, 6, 13], which

\footnotetext{
*e-mail: hassanmanju@gmail.com
}

is inspired by the social behavior of bird flocking and fish schooling. From the literature review, it is observed that a number of papers have published in past few years to solve engineering structural problems. Fourie and Groenwold [8] have applied for size and shape optimization of structures. Schutte and Groenwold [9] have used for optimal sizing design of truss structure and Kovacs et al. [10] have optimized the design of composite structure.

Perez and Behdinan [11] and Chang et al. [12] have used PSOA to generate optimal stacking sequence for structural optimization problems, but not been applied for the ply stacking sequence optimization of composite drive shafts for automobile applications.

In this work, an attempt is made to propose an optimization procedure to design a multilayered E-Glass/Epoxy, HM Carbon/Epoxy and Boron/Epoxy composite drive shafts for given torque, speed and length to achieve minimum weight using PSOA algorithm. The results obtained from the PSOA are compared with the results of GA.

\section{Problem formulation}

It is desirable that a transmission system provides the required torque transmission, increased strength, stability, material resource saving, machining required, building of fail-safe design etc. The common goal in designing a composite drive shaft is to obtain lighter weight shaft under the given functional and geometrical constraints such as static torque transmission capability, torsional buckling and the fundamental natural 
Table 1. Design variables with their limiting values.

\begin{tabular}{lc}
\hline Design variables & Limiting values of the design variables \\
\hline Number of plies $[n]$ & $n>0 ; n=1,2,3 \ldots 32$ \\
Stacking sequence $\left[\theta_{k}\right]$ & $-90 \leq \theta_{k} \leq 90 ; k=1,2 \ldots n$ \\
Thickness of the ply $\left[t_{k}\right]$ & $0.1 \leq t_{k} \leq 0.5$ \\
\hline
\end{tabular}

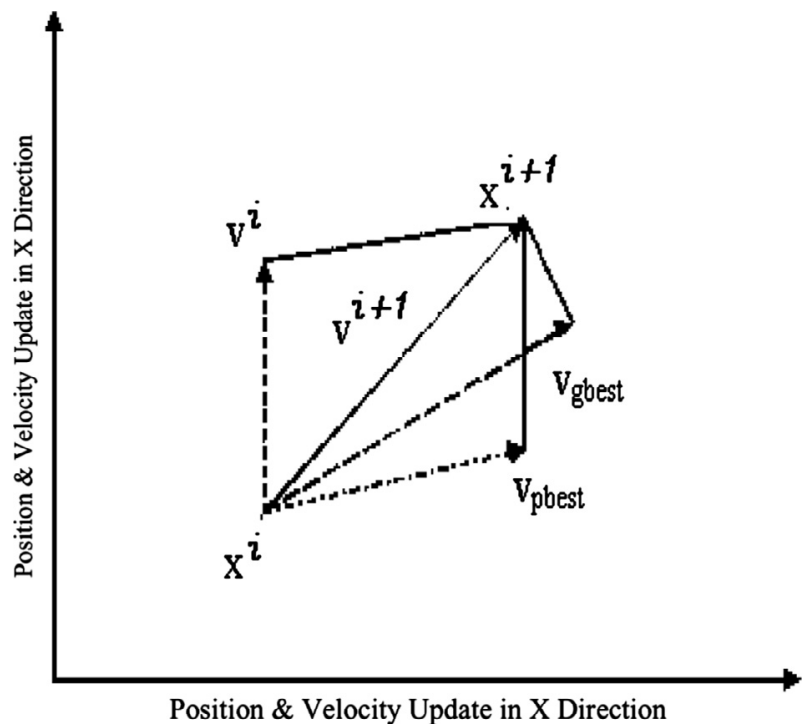

Figure 1. Concept of modification of a searching point.

bending frequency. And design variables as ply thickness, stacking sequence and number of layers.

The objective function considered for the optimum design of composite drive shaft is the minimization of weight given by,

Weight of the shaft, $w=\rho A L$ or $w=\rho \frac{\pi}{4}\left(d_{\mathrm{o}}^{2}-d_{\mathrm{i}}^{2}\right) L$,

where $w=$ weight of shaft, $\rho=$ density of the shaft material, $d_{\mathrm{i}}=$ inner diameter of the shaft, $d_{\mathrm{o}}=$ outer diameter of the shaft, and $L=$ length of the shaft.

For the optimum design of composite drive shaft the design variables considered with their limiting values is shown in Table 1.

\section{Particle swarm optimization algorithm}

In particle swarm optimization algorithm [7, 13], each individual in the particle swarm is composed of three D-Dimensional vectors, where $\mathrm{D}$ is the dimensionality of the search space. The concept of modification of search points is shown in Figure 1 with the current position $X_{i+1}$, the previous best position $X_{i}$, and the velocity $V_{i}$. At each iteration, every particle in the swarm is updated according to equations (2) and (3).

\subsection{Particle swarm optimization algorithm operation}

Initially, particles are initialized by using random number array and number of swarms of certain specified population is taken and fitness function is evaluated for each particle.

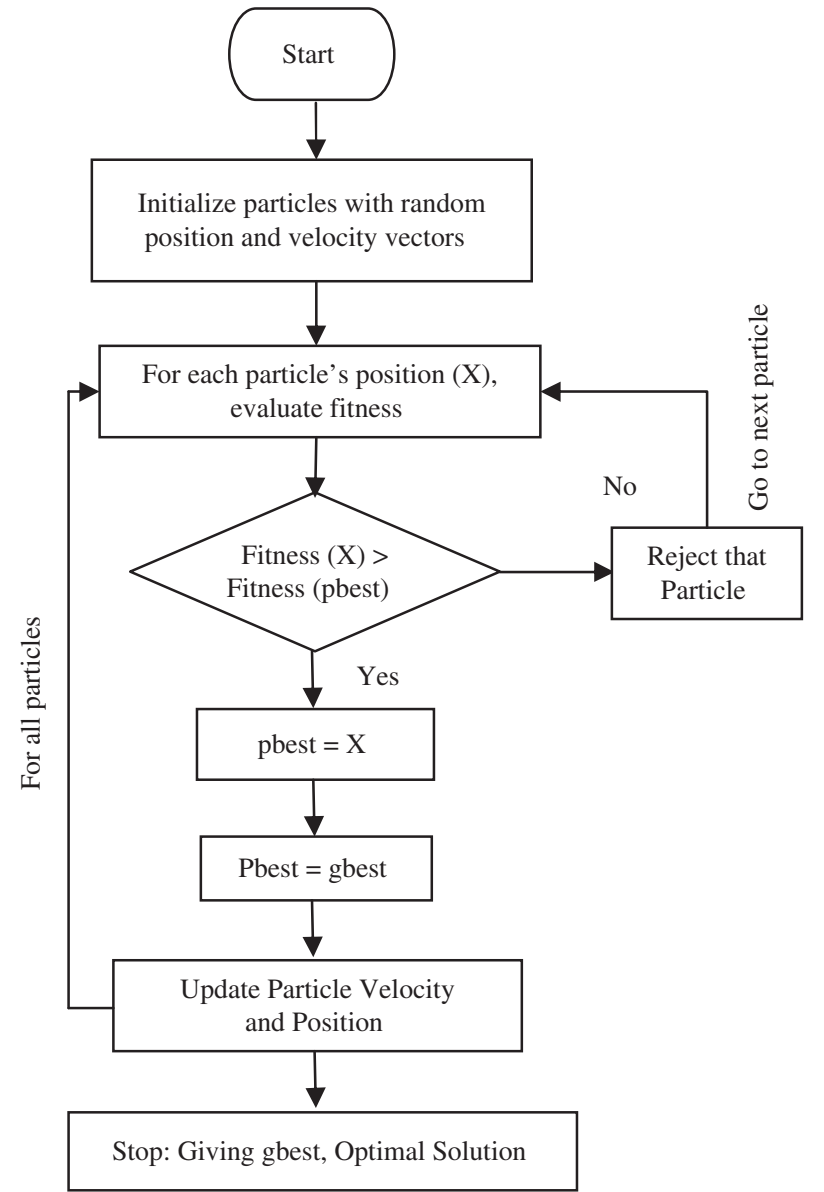

Figure 2. Flow chart of particle swarm optimization.

Table 2. Input parameters to PSOA.

\begin{tabular}{lc}
\hline Inertia weight, $w$ & Varies in between 0 and 1 \\
Random numbers, $r_{1}$ and $r_{2}$ & Varies in between 0 and 1 \\
Leaning factors, $C_{1}$ and $C_{2}$ & 2 \\
Particle size & 50 \\
Number of swarms & 150 \\
\hline
\end{tabular}

From these fitness values, best value or pbest of each swarm is found. If there are 150 swarms, 150 best values or pbests are found, again from these pbests the one global best or gbest value is taken. Now best particle or pbest in the swarm is propelled or updated by using the PSOA's velocity and position equations (2) and (3). If the value is better than the previous, the pbest and gbest is updated and this will repeat until it reaches the maximum number of population. The algorithm repeats the same procedure for all swarms. After completion of the entire loop the best value, which is stored in the gbest will be displayed.

The algorithm of PSOA is given below,

1. Initialize a population array of particles with random positions and velocities on $\mathrm{D}$ dimensions in the search space.

2. Start of loop.

3. For each particle, evaluate the desired optimization fitness function in $\mathrm{D}$ variables. 


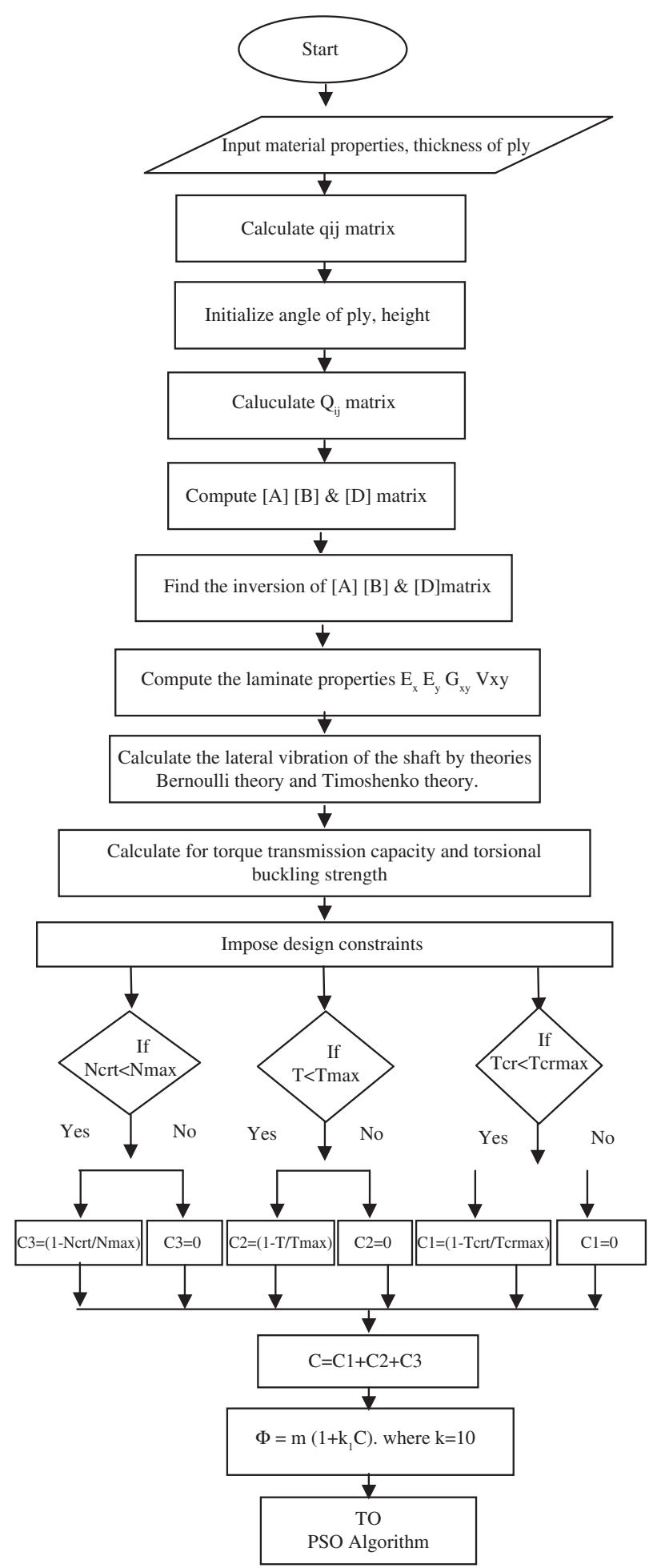

Figure 3. Design algorithm of composite drive shaft.

4. Compare particle's fitness evaluation with its pbesti, if current value is better than previous pbest ${ }_{i}$, then set pbest $_{i}$ equal to the current value, and $X_{i}$ equal to the current location $X_{i+1}$ in D-Dimensional space.

5. Identify the particle in the neighborhood with the best success so far, and assign its index to the variable gbest.

6. Change the velocity and position of the particle according to the to the following equation:

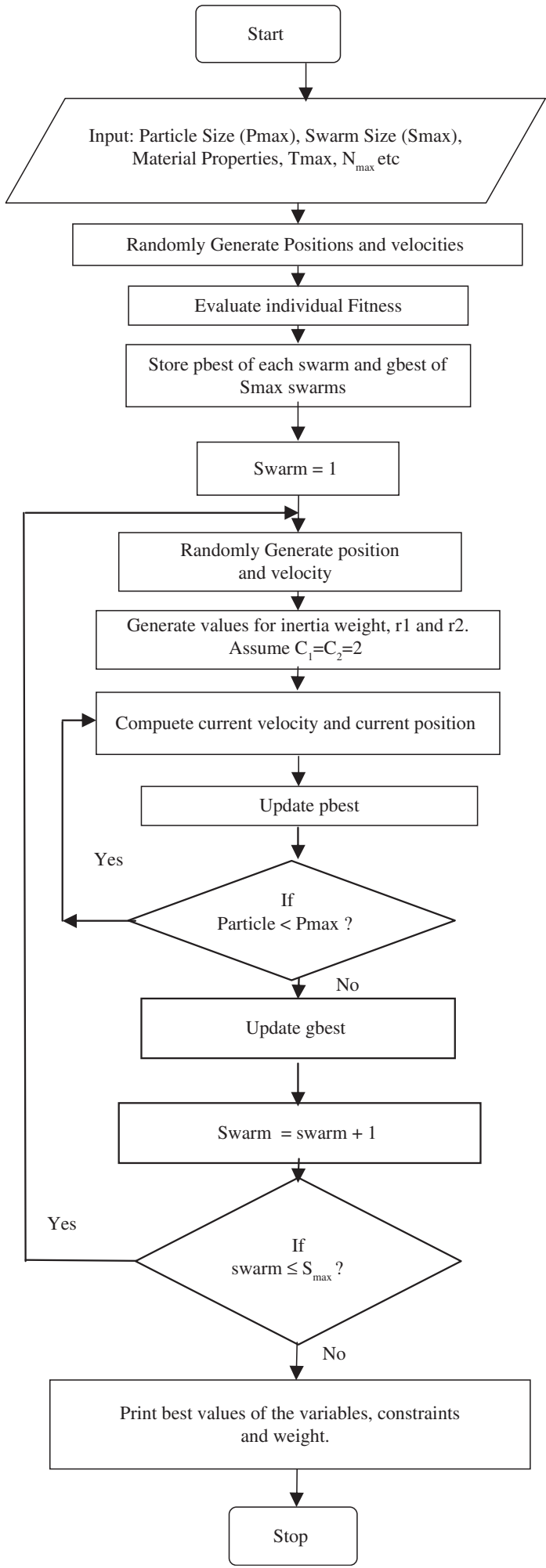

Figure 4. Flow chart of PSA based optimal design of composite drive shaft.

$$
\begin{gathered}
V_{i+1} \leftarrow V_{i} w+C_{1} r_{1}\left(\text { pbest }-X_{i}\right)+C_{2} r_{2}\left(\text { gbest }-X_{i}\right) \\
X_{i+1} \leftarrow X_{i}+V_{i+1}
\end{gathered}
$$


Table 3. Summary of PSOA results.

\begin{tabular}{lcccc}
\hline Parameter & Steel (SM45C) & E-Glass/Epoxy & HM Carbon/Epoxy & Boron/Epoxy \\
\hline Optimum layers & - & 16 & 17 & 2.04 \\
Thickness, $t(\mathrm{~mm})$ & 3.32 & 6.4 & 15 & 1.8 \\
Optimum stacking sequence & - & {$[4 /-13 /-13 /-2 / 67 / 85 /-70 / 18] \mathrm{s}$} & {$[-23 /-51 / 68 /-56 /$} & {$[58 / 61 /-32 /-82 /$} \\
& & & $-72 / 47 /-20 / 46 /-22] \mathrm{s}$ & $-75 /-29 / 21 /-63] \mathrm{s}$ \\
$T(\mathrm{Nm})$ & 3501 & 3508 & 3810 & 3519 \\
$T_{\text {cr }}(\mathrm{Nm})$ & 43,858 & 6520 & 3699 & 3850 \\
$N_{\text {crt }}(\mathrm{rpm})$ & 9320 & 42 & 197 & 9838 \\
Weight $(N)$ & 86 & 51 & 86.89 & 12 \\
Weight saving in $(\%)$ considering & - & & & 85 \\
\multicolumn{1}{l}{ steel shaft weight as datum } & & &
\end{tabular}

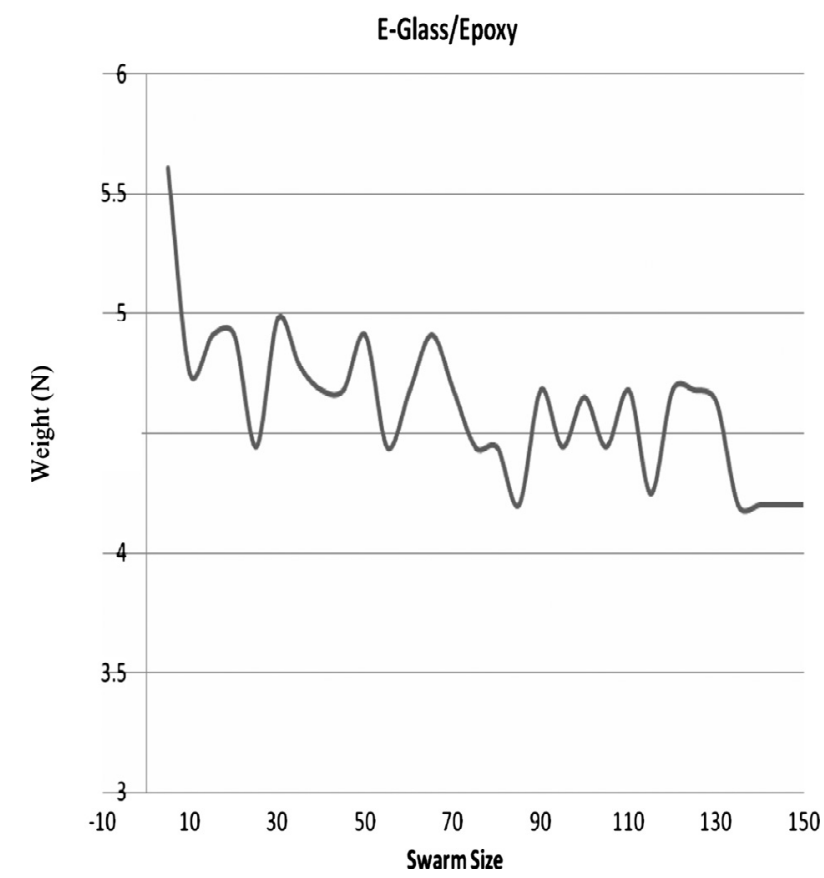

Figure 5. Variations of weight of E-Glass/Epoxy drive shafts with swarm size.

where $w$ is inertia weight, pbest[] \& gbest[] are particle best \& global best, rand() is a random number and $C_{1}$ (cognitive parameter), $C_{2}$ (social parameter) are the learning factors.

7. If a criterion is met (usually a sufficiently good fitness or a maximum number of iterations), exit loop.

8. End loop.

The flow chart describes the working of PSOA as shown in Figure 2 and the input parameters given to PSOA are shown in Table 2.

\section{Results and discussion}

A program is developed using MATLAB V 7 to perform the optimization process and to obtain the best optimal design values. The design algorithm of shaft and the flow-chart

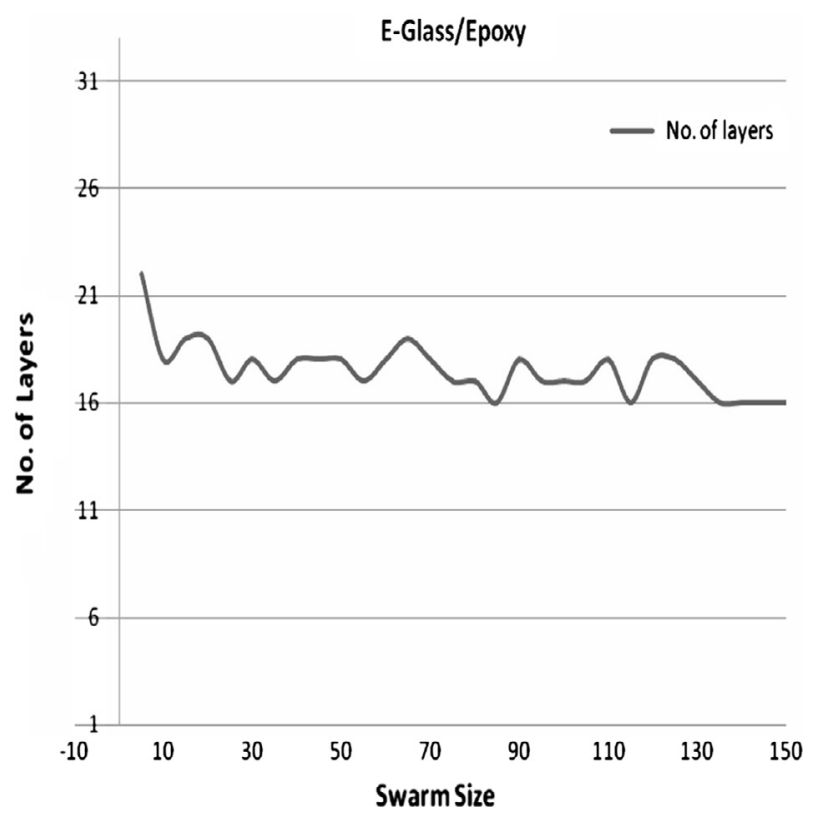

Figure 6. Variations of number of layers of E-glass/Epoxy drive shafts with respect to swarm size.

describing the step by step procedure for optimizing the shaft using PSOA are shown in Figures 3 and 4 respectively. The optimum ply stacking sequence, torque transmission capability, critical speed, weight savings for E-glass, HM Carbon/Epoxy and Boron/Epoxy obtained from PSOA is given in Table 3.

The variation of objective function value of E-glass/Epoxy, HM-Carbon/Epoxy and Boron/Epoxy shafts with respect to swarm size are shown in Figures 5,7 and 9. The variations of number of layers with respect to swarm size of the PSOA are given in Figures 6, 8-10. For the first 135 swarm size of E-glass/Epoxy shaft, 130 swarm sizes of HM-Carbon/Epoxy and 90 swarm sizes of Boron/Epoxy shaft, the weight is found to be fluctuating. The fluctuation is reduced to a minimum from generation numbers 120 in E-Glass/Epoxy, 90 in HM Carbon/ Epoxy and 90 in Boron/Epoxy shaft respectively and later they get converged. Weight of the composite shaft is directly related to the number of layers. As the number of layer increases, weight also increases, therefore fluctuations in weight and number of layers is seen in the Figures 5-10. The percentage 


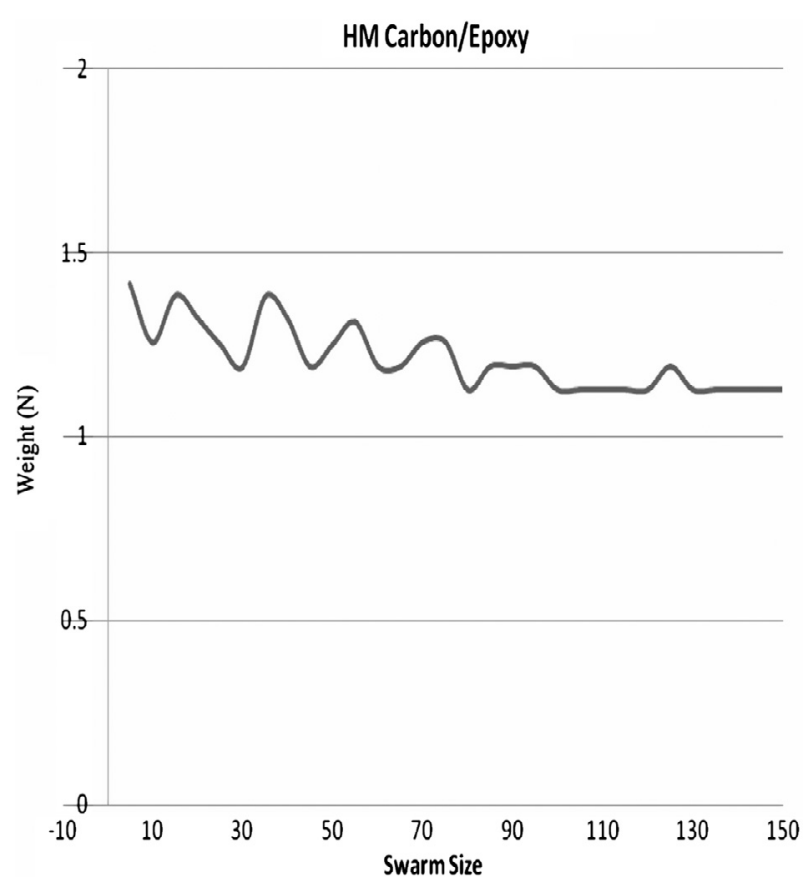

Figure 7. Variations of weight of HM Carbon/Epoxy drive shafts with swarm size.

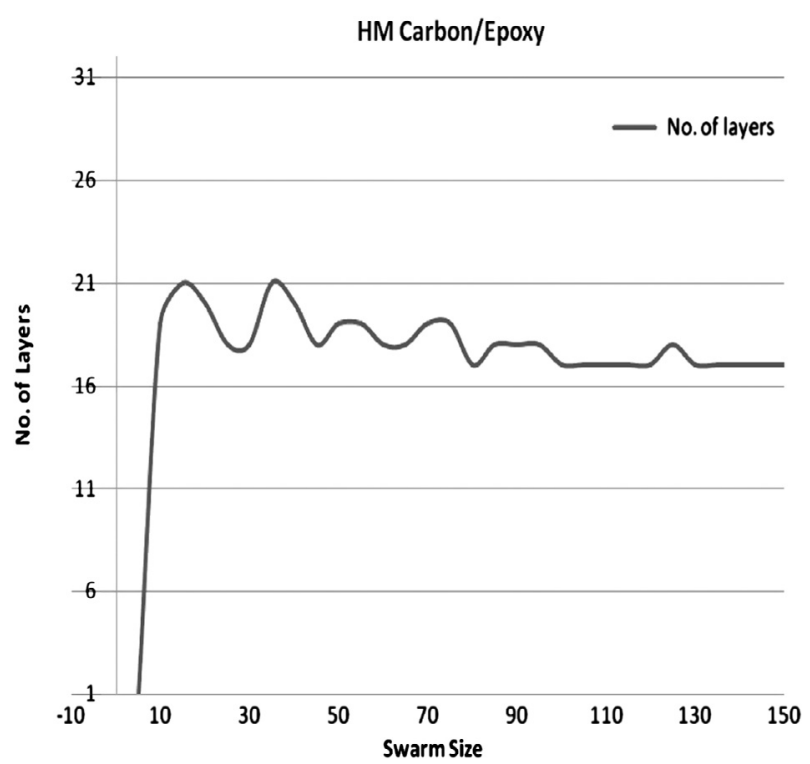

Figure 8. Variations of number of layers of HM Carbon/Epoxy drive shafts with swarm size.

of weight savings of E-glass/Epoxy, HM-Carbon/Epoxy and Boron/Epoxy shafts are $51 \%, 87 \%$ and $85 \%$ respectively taking weight of steel shaft as basis.

\section{Comparison of PSOA and GA results}

The weight obtained from the particle swarm optimization algorithm for E-glass/Epoxy, HM Carbon/Epoxy and Boron/ Epoxy are $42.10 \%, 11.27 \%$ and $12.50 \%$ respectively are

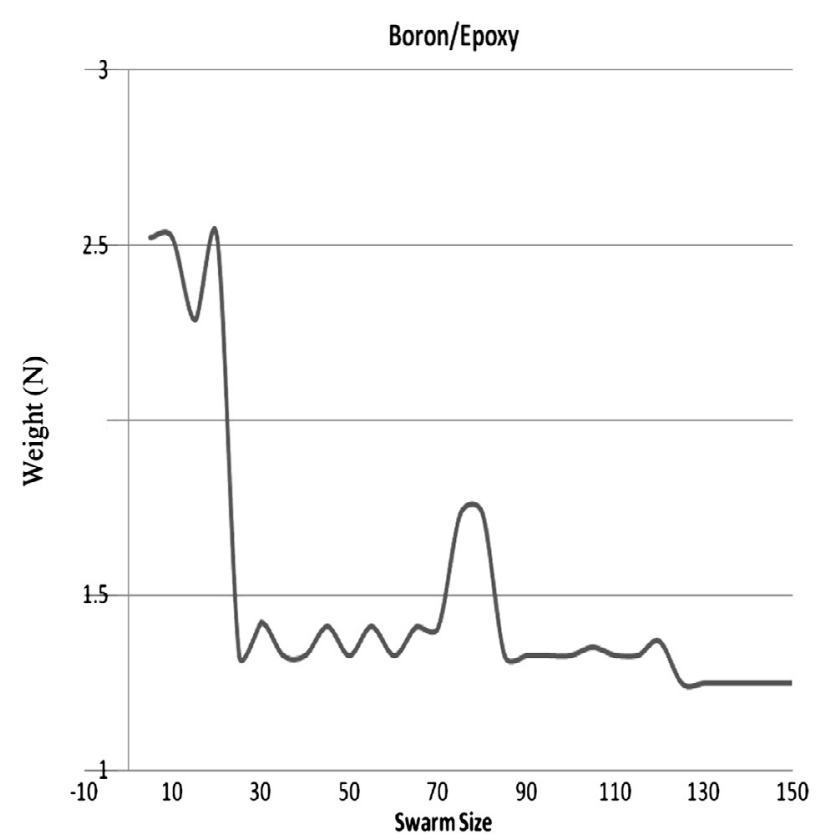

Figure 9. Variations of weight of Boron/Epoxy drive shafts with swarm size.

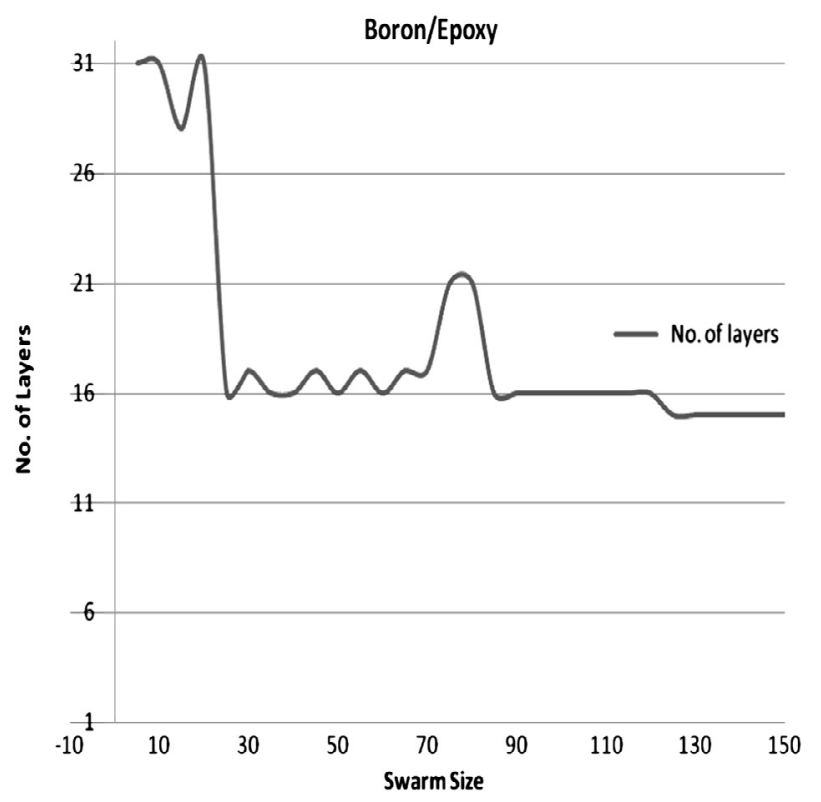

Figure 10. Variations of number of layers of Boron/Epoxy drive shafts with swarm size.

compared with the result of genetic algorithm [4] for E-glass/ Epoxy, HM Carbon/Epoxy and Boron/Epoxy are $44.40 \%$, $11.27 \%$ and $14 \%$ respectively. The Figure 11 shows the weight comparison of E-glass/epoxy, HM Carbon/Epoxy and Boron/ Epoxy composite drive shafts which shows PSOA results are better than GA results. PSOA uses less number of function evaluations and has better searching capability and more computationally efficient than GA for discrete variables problem. 


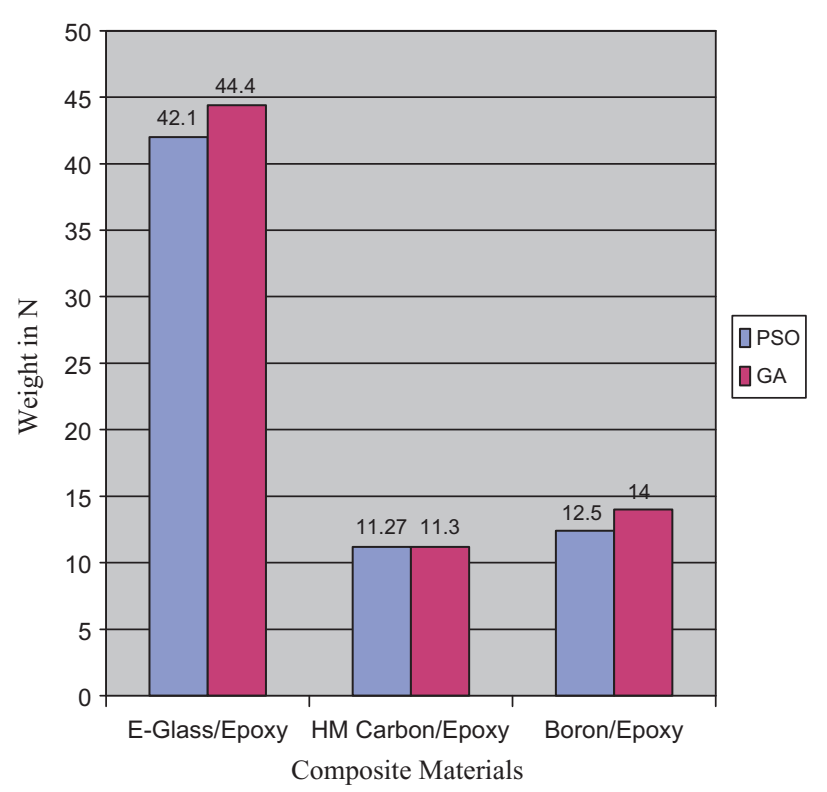

Figure 11. Comparisons of PSA results with GA results [4].

\section{Conclusions}

- An optimization procedure is proposed to design a multilayered single piece composite drive shaft for a given torque, speed and length to achieve minimum weight using PSO approach.

- E-glass/Epoxy, HM Carbon/Epoxy and Boron/Epoxy materials are considered for single piece composite drive shaft.

- An optimal stacking sequence is generated using PSOA to minimize the weight to meet the functional and performance requirements.

- The weight savings of three material shafts using PSOA are compared with Genetic Algorithm results and found that the PSA have better results than GA.

\section{References}

1. Park JH, Hwang JH, Lee CS, Hwang W. 2001. Stacking sequence design of composite laminates for maximum strength using genetic algorithms. Journal of Composite Structures, 52(2), 217-231.

2. Rajendran I, Vijayarangan S. 2001. Optimal design of a composite leaf spring using genetic algorithm. Journal of Computers and Structures, 79(11), 1121-1129.

3. Rangaswamy T, Vijayarangan S, Optimal design and analysis of automotive composite drive shaft. International Symposium of Research Students on Materials Science and Engineering (India, December, 2004), p. 1-9.

4. Rangaswamy T, Vijayarangan S. 2005. Design optimization of composite drives shafts using genetic algorithm. Academic Open Internet Journal, 15, 1-8.

5. Kennedy J, Eberhart RC, Particle swarm optimization. International Proceedings of the IEEE International Conference on Neural Networks (Perth, November, 1995), p. 1942-1948.

6. Eberhart R, Kennedy J, New optimizer using particle swarm theory. International Proceedings of Sixth International Symposium on Micro Machine and Human Science (October, 1995), p. 39-43.

7. Yuhui S, Eberhart RC, Parameter selection in particle swarm optimization. 7-th Annual Conference on Evolutionary Programming (Berlin, 1998), p. 591-600.

8. Fourie PC, Groenwold AA. 2002. The particle swarm optimization algorithm in size and shape optimization. Journal of Structural Multidisciplinary Optimization, 23, 259-267.

9. Schutte JF, Groenwold AA. 2003. Sizing design of truss structures using particle swarms. Journal of Structural Multidisciplinary Optimization, 25, 261-269.

10. Kovacs G, Groenwold AA, Jarmi K, Farks J. 2004. Analysis and optimum design of fiber reinforced composite structures. Journal of Structural Multidisciplinary Optimization, 28, 170-179.

11. Perez RE, Behdinan K. 2007. Particle swarm approach for structural design optimization. Journal of Computers and Structures, 85(19-20), 1579-1588.

12. Chang N, Wang W, Yang W, Wang J. 2009. Ply stacking sequence optimization of composite laminate by permutation discrete particle swarm optimization. International Journal of Structural Multidisciplinary Optimization, 41(2), 179-187.

13. Poli R, Kennedy J, Blackwell T. 2007. Particle swarm optimization - an overview. Springer Science and Business Media, Swarm Intelligent, 1, 33-57.

Cite this article as: Manjunath $\mathrm{K} \& \mathrm{~T}$. Rangaswamy: Ply stacking sequence optimization of composite driveshaft using particle swarm optimization algorithm. Int. J. Simul. Multisci. Des. Optim., 2014, 5, A16. 